\title{
View. The Dutch Critical Care Triage Guideline on Covid-19: Not Necessarily Discriminatory
}

\author{
André den Exter \\ Erasmus School of Law, Erasmus University Rotterdam, Rotterdam, \\ The Netherlands \\ denexter@law.eur.nl
}

\begin{abstract}
Recently, the Dutch Medical Doctors Association (Federatie Medisch Specialisten en de Koninklijke Nederlandsche Maatschappij tot bevordering der Geneeskunst) drafted the 'Covid-19 triage guideline ICU admission' that has age cut-offs that deprioritise or exclude the elderly. Such an age limit for intensive care unit (ICU) admission in case of a national emergency seems discriminatory, and thus, is it inappropriate to use, or not? The question is whether age in itself can be considered as an acceptable selection criterion.
\end{abstract}

\section{Keywords}

Covid-19 - intensive care unit (ICU) triage - age - discrimination

In times of public health emergencies such as the Covid-19 pandemic, there is an ongoing discussion on whether the elderly in need should be deprioritised for admission at intensive care units due to scarcity of ventilators. Recently, the Dutch Medical Doctors Association drafted the 'Covid-19 triage guideline ICU admission' that has age cut-offs that deprioritise or exclude the elderly. ${ }^{1}$ Such

1 'Draaiboek Triage op basis van niet-medische overwegingen voor IC-opname ten tijde van fase 3 in de COVID-19 pandemie' (Covid-19 triage guideline ICU admission), 16 June 2020, https://www.rijksoverheid.nl/documenten/publicaties/2020/o6/16/draaiboek-triage-op -basis-van-niet-medische-overwegingen-voor-ic-opname-ten-tijde-van-fase-3-in-de-covid -19-pandemie, retrieved 23 August 2020. 
an age limit for intensive care unit (ICU) admission in case of a national emergency seems discriminatory, and thus is it inappropriate to use, or not? The question is whether age in itself can be considered as an acceptable selection criterion, thus not as a medical-related criterion.

One may argue that in very exception circumstances, (chronological) age can be a permissible allocation criterion, next to medical criteria (medical need, urgency, etc.). A certain age level then functions as a threshold for deprioritising elderly from the ventilator and critical care beds. Such a differential treatment of the elderly can be justified by the 'fair innings' argument. ${ }^{2}$ The general idea of the fair innings view is that, in the event of competing equal needs, the healthcare interests of the elderly should not be ignored, but should be deprioritised in favour of the younger patient. During their life, the older patient has received the chance to access all necessary healthcare services, and as a consequence, has lived a relatively comfortable and satisfied life and received their 'fair innings', including education, building a career, marriage and starting a family. ${ }^{3}$ As such, the age of - let us say -8 o years, functions as a threshold. The younger patient, however, has not yet received that chance, and consequently will die prematurely if ventilator treatment is denied due to scarce resources. The 'fair innings' theory assumes that the death of a person at the age of 80 is a loss, but unavoidable, as everybody will die when they are older anyway, whereas the death of a young patient is considered a tragedy that could have been prevented by prioritising their treatment. It is emphasised that the health needs of the elderly will not be ignored, meaning that all kinds of necessary care will be provided but aimed at maintaining or improving quality of life, rather than prolonging life. ${ }^{4}$ Age-based rationing proposals therefore do not generally advocate the withholding of all medical treatment from the elderly, but only limited to scarce life-extending care, taking into account relevant circumstances such as survival prospects, and degree of effectiveness or benefits (subtle age rationing) ${ }^{5}$

From a legal perspective, such an age-based threshold is not necessarily discriminatory, taking into account the conditions set by the United Nations Committee on Economic, Social and Cultural Rights (CESCR) in

2 As applied by J. Harris, The Value of Life: An Introduction to Medical Ethics (London: Routledge, 1991), pp. 91-94

3 Ibid.

4 G. Bognar, 'Fair Innings', Bioethics 4 (2015) 251-261, at p. 252.

5 L.M. Fleck, 'Just Caring: In Defense of Limited Age-Based Healthcare Rationing', Cambridge Quarterly of Healthcare Ethics 19 (2010) 27-37, at p. 35. 
General Comment 20, which clarifies the Committee's understanding of nondiscrimination in socio-economic rights. ${ }^{6}$ In the Committee's view:

Discrimination constitutes any distinction, exclusion, restriction or preference or other differential treatment that is directly or indirectly based on the prohibited grounds of discrimination and which has the intention or effect of nullifying or impairing the recognition, enjoyment or exercise, on an equal footing, of Covenant rights. ${ }^{7}$

States must therefore 'immediately adopt measures to prevent, diminish and eliminate the conditions and attitudes which cause or perpetuate substantive or de facto discrimination. ${ }^{8}$

Still, the Committee recognises that some forms of differential treatment can be permissible, provided that 'the justification for differentiation is reasonable and objective. ${ }^{9}$ Moreover, there must be a clear and reasonable relationship of proportionality between the aim sought to be realised and the measures or omissions and their effects. Also important is that 'a failure to remove differential treatment on the basis of the lack of available resources is not an objective and reasonable justification unless every effort has been made to use all resources that are at the State Party's disposal in an effort to address and eliminate the discrimination, as a matter of priority.'10

It means that age-based rationing, to be justified, needs to comply with the Committee's conditions as mentioned above. Here it is argued that the lack of ventilators, critical care beds and scarcity of human resources (intensive care health workers) to operate the life-saving equipment is absolute and not all patients who require intensive care can be admitted. In the most severe scenario when other medical and ethical principles will not work (e.g., 'first come, first served'), and all reasonable State efforts to increase critical care capacity remain unsuccessful, then age may become a reasonable justification for the denial of life-prolonging medical care to the older patient in favour of the younger person with equal medical needs.

So, in the most critical stage of the escalation model (stage $3 \mathrm{C}$ ), the Ministry of Health has to authorise the triggering of the so-called black scenario in

6 CESCR, General Comment (GC) no 20: Non-discrimination in economic, social and cultural rights, $\mathrm{E} / \mathrm{C} 12 / \mathrm{GC} / 2 \mathrm{O}, 2$ July 2009 , para. 7 .

7 Ibid. A similar definition has been used in Art. 1 ICERD; Art. 1 CEDAW; and Art. 2 CRPD.

$8 \quad$ Supra note 6, para. 8.

$9 \quad$ Ibid., para. 13 .

$10 \quad$ Ibid. 
which physicians may exclude a patient from the IC units based on nonmedical criteria as described by the pandemic triage guideline (i.e. priority to health workers, age). Random selection may only be applied as a last resort option when other non-medical criteria are insufficient. By authorising the stage $3 \mathrm{C}$ selection procedure, that approach - when applied correctly - complies with the 'standard of good care', as defined by national law. ${ }^{11}$

So, based on the above-mentioned considerations, age-based rationing in case of the Covid-19 pandemic can indeed be justified to promote general welfare (accessibility of critical care services), while respecting the elderly's health needs, except for life-sustaining treatment. In that case, defining a maximum age (or relative age groups) for age-based rationing is considered an objective standard, to be defined by State Parties, allowing (groups of) individuals the right to participate actively in the decision-making process over the selection of such a criterion ('democratic deliberation'). ${ }^{12}$ That approach then requires access to and disclosure of all relevant information, a transparent and participatory decision-making process regulated by law, and mechanisms for legal redress when rights have been violated. In a way, such a fair and accountable procedure combines both substantive and procedural principles, echoing the accountability for reasonableness standards advocated by Daniels and Sabin. ${ }^{13}$

Although the fair innings argument in age-based rationing has certain weaknesses, it is the least worst of the selection criteria. Alternative criteria (gender, socio-economic status, religion, disability, cost-effectiveness thresholds and random lottery) appear arbitrary and are therefore rejected. When other mechanisms have failed (first come, first served; utility), then limited age-based rationing remains the least onerous, but most necessary, option to cope with the global public health threat.

11 The general standard of 'good care' is the duty of health providers to provide care that is safe, effective, provided at the right time and is patient-centred, and formed by research and consensus within the professional group, preferably laid down in standards, guidelines and protocols, defined by national law under the 'Wet Kwaliteit, Klachten en Geschillen Zorg - Wkkgz' (Law for Quality, Complaints and Disputes of Care), Art. 2. As argued by L.M. Fleck, Just Caring: Health Care Rationing and Democratic Deliberation (New York: Oxford University Press, 20o9), ch. 5; and L.M. Fleck,' Just Caring: Health Care Rationing, Terminal Illness, and the Medically Least Well Off', Journal of Law, Medicine \& Ethics 1 (2011) $156-171$ at p. 164.

13 'Accountability for reasonableness (AfR)' is the idea that the reasons or rationales for important limit-setting decisions should be publicly available. In addition, these reasons must be ones that 'fair-minded' people can agree are relevant to pursuing appropriate patient care under necessary resource restrictions. See N. Daniels and J. Sabin, Setting Limits Fairly: Can We Learn to Share Medical Resources? (New York: Oxford Online, 2009), ch. 4, ebook). 